\title{
Pasados posibles de la música popular: narrativas históricas del jazz y del rock
}

Recepción: septiembre 2020. Aceptación: diciembre 2020.

\section{Resumen}

Este artículo propone repensar las narrativas históricas de la música popular a través de la historiografía del jazz y del rock. Su objetivo es historizar e integrar en estos dos géneros, entendidos como ensamblajes, las maneras de escribir sobre ellos, así como presentar sus inercias historiográficas recurrentes. El artículo se divide en ocho breves secciones. En las cuatro primeras se analiza la escasez de reflexiones historiográficas en los estudios sobre música popular y se clasifican las narrativas históricas dominantes sobre el jazz y el rock, ponderando sus ventajas e inconvenientes. En las cuatro siguientes se examinan los problemas compartidos por estas tramas y se proponen diversas alternativas en relación con los recientes giros historiográficos.

Palabras clave: música popular, jazz, rock, historiografía, narrativas

\section{Passados possíveis da música popular: narrativas históricas do jazz e do rock}

\section{Resumo}

Este artigo propõe repensar as narrativas históricas da música popular através da historiografia do jazz e do rock. 0 seu objetivo é historicizar e integrar nesses dois gêneros, entendidos como assemblages, as formas de escrever sobre eles, assim como apresentar as suas inércias historiográficas recorrentes. $\mathrm{O}$ artigo está dividido em oito seções breves. Nas quatro primeiras, analisa-se a escassez de reflexões historiográficas nos estudos de música 
popular e classificam-se as narrativas históricas dominantes sobre o jazz e o rock, ponderando as suas vantagens e inconvenientes. As quatro seções seguintes examinam os problemas partilhados por esses enredos e propõem várias alternativas em relação às recentes reviravoltas historiográficas.

Palavras-chave: música popular, jazz, rock, historiografia, narrativas

\title{
Possible Pasts of Popular Music: Historical Narratives of Jazz and Rock
}

\begin{abstract}
This article proposes to rethink historical narratives of popular music through the historiography of jazz and rock. Its objective is to historicize and integrate in these two genres, understood as assemblages, the ways of writing about them, as well as to present their recurring historiographical inertias. It is divided into eight short sections. The first four analyze the scarcity of historiographical reflections in popular music studies and classify the dominant historical narratives on jazz and rock, considering their advantages and disadvantages. The following four examine the problems shared by these emplotments and propose several alternatives in relation to the recent historiographical turns.
\end{abstract}

Keywords: Popular music, jazz, rock, historiography, narratives

Anualmente se publican decenas de historias del jazz y del rock. No podía ser de otra forma en dos temas tan mediados por la pervivencia del pasado. Sin embargo, las reflexiones historiográficas no han sido abundantes en los estudios sobre música popular. En los escritos no académicos, esa escasez se vuelve ausencia. De hecho, las definiciones más aceptadas de la expresión "música popular" han partido siempre de criterios actuales o "presentistas" que dificultan su aplicación histórica (Johnson, 2018). Si la ontología de los géneros musicales se ha transformado considerablemente en los últimos años, en muchos casos para insistir en la relevancia de su génesis y sus mediaciones (Fabbri, 2012; Drott, 2013; Piekut, 2014; Brackett, 2016; Born y Barry, 2018), parece el momento adecuado para repensar las maneras de escribir sobre su pasado. Entiendo aquí el jazz y el rock como ensamblajes de sonidos, prácticas performativas, convenciones sociales y estéticas, identidades culturales, circunstancias materiales, instituciones, espacios, objetos, emociones y formas de escucha, cuyas propiedades no son intrínsecas sino emergentes, es decir, producidas en 
el tiempo por la intra-acción de sus componentes (Barad, 2007; De Landa, 2011, pp. 15-16). A través de ejemplos de estos dos géneros musicales, el objetivo de estas páginas es reflexionar sobre las narrativas históricas de la música popular, presentar sus problemas recurrentes y algunas propuestas de futuro.

Este artículo se ocupa solo de textos escritos. La decisión se debe tanto a cuestiones de espacio como a la especificidad de la narrativa audiovisual, que requeriría el análisis de parámetros y recursos técnicos diferentes. Por otra parte, la elección del jazz y del rock responde a cuatro razones básicas. En primer lugar, se trata de dos géneros representativos pero concretos, que permiten cierta exhaustividad en el diagnóstico. En segundo lugar, el jazz y el rock se han visto particularmente marcados por la nostalgia en las últimas décadas (Reynolds, 2012). En tercer lugar, la decisión busca explorar formas historiográficas alternativas de lidiar con géneros musicales hegemónicos. La cuarta razón responde a examinar dos géneros de la música popular durante décadas considerados antitéticos, para analizar tanto sus confluencias tanto históricas como historiográficas. Para examinar un corpus abarcable, excluiré las narrativas deliberadamente nacionales y me referiré a historias que pretenden ser generales en términos de espacio y tiempo.

\section{Historiografía de la música popular}

A lo largo de los años ochenta y noventa, con los estudios sobre música popular polarizados entre los estudios culturales y la semiótica, ambos particularmente interesados en la sincronía, la reflexión histórica no fue prioritaria en publicaciones académicas como Popular Music o Popular Music and Society. En 2004 se fundó la revista Popular Music History, editada por Dave Laing, en parte con el fin de subsanar esa laguna. En su primer número, Charles Hamm señaló que los estudios de música popular raramente lidiaban con procesos de larga duración. Tras un análisis de los artículos publicados en Popular Music desde su fundación en 1981, constató que casi todos eran sobre música posterior a 1955 y la gran mayoría trataban temas coetáneos a la revista. Su conclusión fue que el campo de los estudios sobre música popular se había desarrollado como una disciplina "ahistórica" (Hamm, 2004). Los números siguientes de Popular Music History supusieron un notable avance de la reflexión historiográfica en el campo. Sin embargo, la revista no publicó números en 2005, 2006 y 2017, solo uno en 2018 y 2019, y desde 2009 ha tendido hacia el análisis sincrónico del pasado. Que no haya tenido la continuidad deseada confirma quizá la tesis de Hamm. 
Por otra parte, en la mayoría de los manuales teóricos más relevantes de los últimos treinta años, que han asentado las bases ontológicas y epistemológicas del estudio de la música popular, el tema tampoco se ha considerado importante. The Popular Music Studies Reader, editado por Andy Bennett, Barry Shank y Jason Toynbee en 2006, no incluía entre sus más de cuarenta artículos ninguno sobre cuestiones historiográficas, y de los más de treinta de The SAGE Handbook of Popular Music (2015), solo dos estaban dedicados a reflexiones sobre el tema: uno de Matt Brennan sobre la historia de la música en directo y otro de Christine Feldman-Barrett sobre la investigación archivística como modo de ampliar nuestro conocimiento histórico, este último revelador de las fuentes predominantes en el actual estudio de la música popular. Las excepciones a esta desidia historiográfica han sido Studying Popular Music, de Richard Middleton (1990), Popular Music in Theory, de Keith Negus (1996) y Studying Popular Music Culture, de Tim Wall (2013). En el caso de Middleton, si bien cinco páginas de trescientas no parecen suficientes para abordar debidamente el problema de cómo escribimos sobre la música popular del pasado, al menos le permitieron señalar cuestiones básicas de contextualismo, intertextualidad histórica y temporalidad múltiple (Middleton, 1990, pp. 11-16). Por su parte, el libro de Negus es único por dedicar un capítulo a los problemas conceptuales y epistemológicos de lo que se ha denominado "la era del rock", esto es, el período comprendido entre la difusión masiva del rock and roll, en 1955, y el ocaso del punk como subcultura, a finales de los años setenta (Negus, 1996, pp. 136-163). Mediante el análisis del "imperialismo del rock", Negus cuestionó las narrativas de la música popular como relatos orgánicos de géneros autorreferenciales que representaban épocas, y demandó "otras maneras de contar la historia".

El manual de Tim Wall es la monografía más reciente y también más exhaustiva de análisis historiográfico de la música popular. Su primer capítulo cuestiona cuatro inercias concretas: las historias totalizadoras, que eligen los momentos relevantes en función de una narrativa coherente; la dicotomía estricta entre mainstream y underground; la búsqueda retrospectiva de las raíces musicales de un género; y la idea de que la música popular ha sido más uniforme en el pasado (Wall, 2013, pp. 3-16). Sin embargo, su planteamiento de que cada momento representa una "cultura" de la historia de la música popular vuelve ese concepto tanto esencialista como estático, y por tanto, improductivo. Un volumen editado recientemente por Sarah Baker, Catherine Strong, Lauren Istvandity y Zelmarie Cantillon constituye la publicación colectiva más importante sobre la historia en los estudios sobre música popular y, a la vez, la prueba de que estos son un campo absolutamente poroso y transversal en relación 
con otras disciplinas cuando tratan cuestiones de imagen, de clase, raciales o de género, pero autorreferencial a la hora de repensar la historia, el tiempo o la causalidad (Baker et al., 2018).

Las razones de esta escasa reflexión histórica en los estudios de música popular son múltiples. Por una parte, se han naturalizado durante décadas el tiempo y los "regímenes de historicidad" (la manera en que se configuran las relaciones entre pasado, presente y futuro) que condicionan las historias posibles (Hartog, 2002). Por otra, se ha descuidado el análisis de los relatos sobre el pasado de la música popular. Las tramas narrativas no han sido un objeto de estudio recurrente en la disciplina, a pesar de su obvia importancia en la fosilización del canon. Hay contadas pero notables excepciones a esta omisión. En 1990, Sarah Thornton identificó cuatro criterios por los cuales se asigna importancia histórica a un evento de la música popular: ventas, interés biográfico, recepción por la crítica y cobertura mediática. Según ella, cada criterio generaba una "estrategia" diferente de ordenar el pasado que consistía, respectivamente, en escribir listados, biografías, erigir un canon o tomar las publicaciones especializadas como "ventana" al pasado (Thornton, 1990, pp. 87-89). Por su parte, Simon Frith dividió en 2007 las narrativas históricas de la música popular en cinco modelos: el basado en la industria; el musicológico, estructurado en géneros y estilos; el sociológico, en el que los cambios musicales reflejan los cambios sociales; el histórico, que discurre cronológicamente; y el de la historia del arte, dedicado a figuras y piezas musicales trascendentes (Frith, 2007). Ambas clasificaciones simplifican demasiado cada narrativa y son poco operativas porque tantos sus "criterios" como sus "estrategias" se superponen a menudo y resulta complicado encontrar ejemplos que sigan estrictamente uno de los modelos, por lo que no han tenido mucha repercusión práctica.

Un intento más sistemático de clasificación es Stories We Could Tell, libro que David Sanjek escribió hace unos quince años y fue actualizando hasta 2007, pero dejó inédito al fallecer prematuramente en 2011. El original fue recuperado de su ordenador y publicado en 2019. Sanjek dividió las historias de la música popular estadounidense en ocho narrativas: instintiva, darwiniana, heroica, ritual, aluvial, agorafóbica, maniquea y mítica. Como ha señalado Dai Griffiths, la taxonomía es desigual, confusa, cuando no abiertamente equívoca (como su uso de la palabra "agorafobia" para designar el recelo hacia el mercado), y sus narrativas se solapan continuamente (Griffiths, 2019). Atraviesa todo el libro un marcado discurso que subraya la excepcionalidad estadounidense en la música popular, en ocasiones incluso una narrativa heroica, y su llamamiento final a un enfoque 
"horizontal", que se traduce sencillamente en más contextualización y una cierta antipatía por el análisis musical, suena ya obsoleto (Sanjek, 2019, pp. 201-213). También llama la atención la práctica ausencia en el volumen de referencias bibliográficas de historiadores o filósofos de la historia, así como la escasa reflexión sobre el tiempo y la causalidad. En todo caso, se trata de un proyecto sin precedentes en la historiografía de la música popular.

\section{Narrativas históricas y tramas literarias}

En cuanto a los estudios específicos sobre los relatos históricos del rock y del jazz, son todavía más escasos. En el caso del primero, Juliana Guerrero (2010) ha analizado las narrativas históricas del rock nacional argentino, mayoritariamente configuradas desde criterios extramusicales, y Erin Torkelson Weber (2016) ha mostrado que la historia de The Beatles ha seguido cuatro narrativas fundamentales, enmarcadas por acontecimientos cruciales en la recepción de la banda de Liverpool. En lo referente al jazz, Scott DeVeaux publicó en 1991 “Constructing the Jazz Tradition”, un artículo historiográfico que se considera el inicio de los llamados $\mathrm{New}$ Jazz Studies (O’Meally, Edwards y Griffin, 2004; Tucker, 2012). DeVeaux, musicólogo especialista en el bebop, identificaba en su artículo una "historia oficial del jazz" que se ajustaba a una narrativa orgánica por estilos:

El jazz se presenta como un todo coherente, y su historia como una narración hábilmente elaborada y fácilmente comprensible. Después de una obligatoria alusión a los orígenes africanos y al ragtime como antecedente, se muestra que la música se ha desarrollado a través de una sucesión de estilos o períodos, cada uno con una etiqueta y un período de tiempo convenientemente distintivos: el jazz de Nueva Orleans hasta la década de 1920, el swing en la de los treinta, el bebop en los cuarenta, el cool y el hard bop en la de los cincuenta, el free jazz y la fusión en los sesenta. Los detalles del énfasis varían. Pero, de un manual a otro, existe un acuerdo sustancial sobre las características definitorias de cada estilo, el panteón de los grandes innovadores y el canon de las grabaciones maestras (1991, p. 525). ${ }^{1}$

\footnotetext{
1 "Jazz is presented as a coherent whole, and its history as a skillfully contrived and easily comprehended narrative. After an obligatory nod to African origins and ragtime antecedents, the music is shown to move through a succession of styles or periods, each with a conveniently distinctive label and time period: New Or-leans jazz up through the 1920s, swing in the 1930s, bebop in the 1940s, cool jazz and hard bop in the 1950s, free jazz and fusion in the 1960s. Details of emphasis vary. But from textbook to textbook, there is substantive agreement on the defining features of each style, the pantheon of great innovators, and the canon of recorded masterpieces".
} 
A pesar de que el artículo de DeVeaux es el texto más citado de los estudios recientes sobre el jazz, la narrativa evolucionista y estilística sobre este género musical ha mostrado una resiliencia extraordinaria. No solo se acomodan a ella los manuales clásicos más leídos y que cuentan con numerosas ediciones en varios idiomas, como los de Joachim Berendt (1998), Mark Gridley (2011), Frank Tirro (2016) o Ted Gioia (2018), sino también la historia del jazz publicada recientemente por el propio DeVeaux en colaboración con el crítico Gary Giddins (2009). En 2010, Ken Prouty todavía lamentaba la escasa correspondencia entre las introducciones de los manuales sobre jazz, tan críticas con el canon, y sus contenidos, apegados a las narrativas de siempre (Prouty, 2010, p. 43). La clave de tal perdurabilidad reside en la vigencia de este relato como proyecto social y político de la modernidad, no desvinculado de una cierta forma de nacionalismo. El propio DeVeaux proporcionaba ya una explicación plausible en su artículo de 1991:

La narrativa histórica aceptada para el jazz [...] es un pedigrí que muestra que el jazz contemporáneo no es una tendencia o una mera música popular, sujeta a los caprichos de la moda, sino un arte autónomo de cierta sustancia, la culminación de un largo proceso de maduración que a su manera recapitula el progreso evolutivo del arte occidental. El giro adicional es que esta nueva música clásica estadounidense reconoce abiertamente su deuda no con Europa, sino con África. Hay un sentido de reversión triunfante, ya que la música de un pueblo anteriormente esclavizado es designada por el Congreso como un "tesoro nacional estadounidense raro y valioso" y difundida en el extranjero como un arma de la Guerra Fría (p. 526). ${ }^{2}$

Aplicando la clasificación metahistórica de Hayden White (romance, tragedia, comedia y sátira), DeVeaux explicaba esta trama dominante como un romance, un relato heroico del triunfo del bien sobre el mal, de la luz sobre las tinieblas (1991, p. 533). Más llamativamente, terminaba asumiendo que el romance era la narrativa que él mismo adopataba en sus clases para transmitir un sentimiento de orgullo del patrimonio musical estadounidense (DeVeaux, 1991, p. 552). En efecto, el romance es la trama literaria triunfante de la modernidad y del humanismo, porque representa

2 "The accepted historical narrative for jazz [...] is a pedigree, showing contemporary jazz to be not a fad or a mere popular music, subject to the whims of fashion, but an autonomous art of some substance, the culmination of a long process of maturation that has in its own way recapitulated the evolutionary progress of Western art. The added twist is that this new American classical music openly acknowledges its debt not to Europe, but to Africa. There is a sense of triumphant reversal as the music of a formerly enslaved people is designated a 'rare and valuable national American treasure' by the Congress and beamed overseas as a weapon of the Cold War". 
la superación del pasado y la victoria de lo ideal sobre lo material, de la cultura sobre la naturaleza. Esta es seguramente la razón principal por la que, aunque muchas biografías están construidas como tragedias, las narrativas de la música popular suelen compartir la trama del romance, basada en la metáfora del pasado como una lucha o un viaje aventurado y fascinante. También es el motivo por el cual tantas historias del jazz y del rock terminan, respectivamente, en los años sesenta y setenta, es decir, una vez finalizado su proceso de legitimación como arte.

El romance como arquetipo historiográfico de la música popular se construyó en los años cincuenta (Gennari, 2006, pp. 137-154; Hardie, 2013) contra la celebración del pasado de la narrativa purista previa, que contextualizaba la música en un tiempo paralelo en el que los cambios y la interacción con la modernidad se minimizaban para no afectar a la "autenticidad" de sus protagonistas. Esa autenticidad describe una música antes de que la modernidad y la tecnología le afecten, la musealiza; con ello, restringe el cambio al mainstream de la música popular. Este es el modelo que siguieron las primeras historias del jazz, como Jazzmen, una colección de ensayos editada por Frederick Ramsey Jr. y Charles Edward Smith (1939), The Real Jazz de Hugues Panassié (1942), Shining Trumpets de Rudi Blesh (1947) o Historia del jazz de Néstor Ortiz Oderigo (1952). Todas ellas mitificaban Nueva Orleans y el Chicago de la primera mitad de los años veinte como el paraíso perdido del jazz, una época de autenticidad y masculinidad afroestadounidenses pronto caídas en decadencia a causa del capitalismo y su sentimentalidad. También ha sido la trama predilecta de los historiadores del blues de Delta, como Robert Palmer (1982), Alan Lomax (1993) o, más recientemente, Ted Gioia (2010).

\section{Historias orgánicas del jazz y del rock}

Uno de los principales riesgos de clasificar narratológicamente las historias de la música popular es mezclar géneros literarios, estrategias de organización y criterios disciplinares. El uso del romance, la tragedia, la comedia o la sátira condiciona pero no determina por completo la organización de las historias, que en general pueden seguir una estructura orgánica o evitarla. Las historias orgánicas son mayoritarias y presentan formas diversas en función de si toman como referencia básica la biografía, el género musical o el estilo. El modelo biográfico está presidido por grandes figuras (casi exclusivamente masculinas) que a juicio de quien las elige han hecho contribuciones fundamentales a la música popular. Este tipo de narrativa es la que predomina en historias del jazz como The 
Swing Era de Gunther Schuller (1989) y Visions of Jazz: The First Century de Gary Giddins (1998), o en The Rolling Stone Illustrated History of Rock and Roll (1976, tercera edición en 1992). Sus puntos débiles son que privilegia la agencia individual por encima de la interacción y oscurece tanto los factores sociales como las cuestiones de campo en favor del talento personal. Precisamente por su facilidad para eludir estas mediaciones, el modelo biográfico se superpone a menudo con una narrativa purista. La mayoría de las historias esencialistas del jazz y del blues mencionadas anteriormente adoptan narrativas individuales en las que cada músico representa una vertiente distintiva de la autenticidad.

La trama biográfica también ha sido recurrente en numerosas publicaciones que, en las tres últimas décadas, han rebatido el androcentrismo de las historias del jazz y del rock (Gaar, 1992; O’Brien, 1996; O’Dair, 1997; Vélez, 2018). Por necesarios que sean este tipo de estudios inclusivos, pueden llevar a reforzar las narrativas dominantes, ya que agrandar el canon sin cuestionar sus lógicas implica compartir y fosilizar sus criterios de valor. El proyecto de integrar cada vez más cantantes e instrumentistas en el canon del rock o del jazz compartimentándolas en la categoría "mujeres en la música popular" continúa marginándolas al definirlas primero desde su género y solo secundariamente como músicas (Kearney, 2005, p. 211; Ramos, 2010; Liska, 2014). En este sentido, conviene que la trama biográfica no dificulte una concepción relacional e histórica, y culturalmente situada del género, que permita tanto explorar la intersección de la categoría "mujer" con otras identidades como develar las asociaciones entre tecnología y masculinidad. Como ha escrito John Wallach Scott (en Wallach et. al, 2011, p. 38), si la clase, la raza, la sexualidad o la religión desempeñan un papel igualmente significativo en la definición del concepto "mujer", el género no puede ser unas perspectiva de análisis autosuficiente.

La historia orgánica aplicada a los géneros musicales entiende estos como entidades que surgen, se desarrollan y entran en decadencia. Se trata, en cierta medida, de convertir al género en el sujeto biografiado. En esta narrativa, determinadas músicas son tratadas teleológicamente y solo en la medida en la que alimentan aquello que representa el centro de la historia, a menudo el jazz, el rock, o ambos. Acaso el modelo más conocido sea The Rise and Fall of Popular Music: A Narrative History from the Renaissance to Rock'n'Roll, de Donald Clarke (1995), en la que, a pesar del título, se dedican unas treinta páginas a los "orígenes" entre el siglo XV y 1900, casi quinientas al jazz y al rock'n'roll, y otras treinta a certificar la muerte de la música popular en 1970. Otro buen ejemplo sería The Seventh Stream: The Emergence of Rock'n'Roll in American Popular Music, del sociólogo 
estadounidense Philip H. Ennis (1992), un libro en el que el rock se explica como síntesis de seis "corrientes" anteriores: el pop, identificado con Tin Pan Alley; el pop afroestadounidense, compuesto principalmente por los derivados del blues, el country, el jazz, el folk y el góspel. Su primera parte explora cómo se formaron estas seis corrientes desde 1900, mientras la segunda trata el "nacimiento" del nuevo género y la tercera se centra en el período de "madurez" del rock entre 1965 y 1970. El libro termina con un capítulo titulado "The Pause Point", según el cual el rock se estancó en 1970 porque se separó de la juventud, debido a "la ausencia de un movimiento creativo" y a "las enojosas mezclas" con el pop, el country y el soul (Ennis, 1992, pp. 344 y 360). Según Ennis, lo que siguió a 1970 fue la decadencia marcada por la diversificación y la comercialización: el declive se produce cuando lo nuevo entra a formar parte del mainstream.

Otra trama orgánica es la dividida en estilos, la más abundante y la que suelen seguir las historias académicas para estudiantes. Se basa en la sucesión de diferentes prácticas musicales definidas por normas o características formales particulares dentro de uno o varios géneros. Los ejemplos son numerosos tanto en el jazz, con Jazz: A History de Frank Tirro (1977, tercera edición en 2016), Jazz Styles: History and Analysis de Mark Gridley (1978, undécima edición en 2011) y The History ofJazz, de Ted Gioia (1997, tercera edición en 2018), como en el rock, con Rock and Roll: Its History and Stylistic Development, de Joe Stuessy y Scott D. Lipscomb (1990, séptima edición en 2012), Rock Music Styles: A History, de Katherine Charlton (1990, séptima edición en 2014), o What's that Sound: An Introduction to Rock and Its History, de John Covach (2006, quinta edición en 2018). Las historias estilísticas incluyen a menudo una narrativa teleológica para las manifestaciones musicales anteriores al género analizado, como en el caso de las de Stuessy y Lipscomb o Charlton, que dedican sus primeros capítulos al ragtime, Tin Pan Alley, el jazz, el blues, el góspel y el country como "raíces" del rock, de modo similar a Ennis. No se puede negar el valor pedagógico de los estilos, su papel estético y su mediación tanto en la creatividad como en la escucha. Sin embargo, también es cierto que unifican, esencializan, privilegian la estabilidad sobre el cambio, difuminan la participación de diversos agentes, refuerzan la idea de autonomía de la música, perpetúan el canon y el modelo centro-periferia, y dificultan el conocimiento interdisciplinar.

\section{Historia sociocultural versus historia formalista}

El contrapunto habitual a estas narrativas orgánicas es la historia sociocultural, que tiende a presentar la música popular en función de 
acontecimientos sociales, económicos, culturales o políticos. Durante décadas se privilegiaron las narrativas homológicas, en las que la música era un mero reflejo de las circunstancias del período: The Sound of the City, en la que Charlie Gillett (1970) analizaba el devenir del rock a partir de la industria discográfica, y Urban Rhythms, una historia de subculturas y resistencias juveniles escrita por Iain Chambers (1985), son brillantes arquetipos de dicha trama. No obstante, en las últimas décadas se ha combinado esta perspectiva con otra basada en teorías de la interpelación e incluso de la narratividad, típicas de los estudios culturales a partir de los años noventa, en las que la música también tiene el poder de construir identidades y de cambiar coyunturas (Vila, 1996). Esta narrativa suele eludir los estilos musicales y el sonido en general. Un ejemplo claro es Why Jazz Happened?, de Mark Myers (2013), en el que la historia del jazz entre 1945 y 1972 se explica en función de diez "eventos externos". Myers considera que:

Antes de la Segunda Guerra Mundial, el principal benefactor de la creciente popularidad del jazz fue la industria discográfica. [...] Por el contrario, durante los veintisiete años que siguieron a la Segunda Guerra Mundial, el jazz fue remodelado con frecuencia por eventos externos. De 1945 a 1972, los diez principales estilos de jazz que surgieron ciertamente reflejaron sus épocas. Pero en lugar de ajustarse a modelos establecidos de blues y de baile, el jazz comenzó a filtrarse a través de las perspectivas de artistas individuales en lugar de únicamente a través de los intereses comerciales de algunas grandes compañías discográficas. [...] Los años 1942 a 1972 siguen siendo los más prolíficos, dinámicos y significativos para la evolución del jazz. Durante este período crítico, los estilos de jazz cambiaron más rápidamente que en las décadas anteriores, y más profundamente que en los años siguientes (2013, pp. 5 y 9). ${ }^{3}$

Myers asume aquí la opinión de algunos críticos y músicos de jazz relevantes entre los años cuarenta y sesenta sobre la complejidad y superioridad de aquella época frente a la anterior y la posterior, un intento de separar arte y música popular. Además, minimiza el papel de los artistas, así como

\footnotetext{
3 "Before World War II, the chief benefactor of jazz's widening appeal was the recording industry. [...] By contrast, during the twenty-seven years that followed World War II, jazz was reshaped frequently by external events. From 1945 to 1972, the ten major jazz styles that emerged certainly reflected their times. But instead of conforming to proven blues and dance models, jazz began to be filtered through the viewpoints of individual artists rather than solely through the commercial interests of a few large record companies. [...] The years from 1942 to 1972 remain the most prolific, dynamic, and significant for the evolution of jazz. During this critical period, jazz styles changed more rapidly than in the preceding decades -and more profoundly than they did in the years that followed".
} 
la agencia específica de la música y sus formas de escucha en la historia del jazz, en favor de la labor y opinión de instituciones, productores y críticos, reduciendo la causalidad a la organización social de la producción y el consumo. Otro ejemplo claro de la narrativa sociocultural en la música popular es All Shook Up: How Rock'n'Roll Changed America, de Glenn C. Altschuler (2003), en el que rock de los años cincuenta y sesenta se interpreta en sus confluencias con diversos conflictos sociales en los Estados Unidos de esta época, tanto raciales (segundo capítulo) como sexuales (tercero), generacionales (cuarto) y mediáticos (quinto).

En algunos casos, se enfatizan cuestiones estéticas y los estilos pasan a ser "culturas" que incorporan cuestiones tanto musicales como sociales. Este concepto de "cultura" no la entiende ya como un grupo de gente cuya estética representa una forma de resistencia social y generacional coherente y autónomo, a la manera de los estudios subculturales británicos de los años setenta, sino como una forma de distinción llevada a cabo por un grupo humano heterogéneo y elástico. En todo caso, tal perspectiva continúa reificando estas "culturas" (heavy metal, punk, reggae, hip hop, dance) como entidades estables, separadas y equiparables a períodos (críticas a menudo aplicadas al "estilo"). Este es el caso del influyente libro Cultures of Popular Music, de Andy Bennett (2001), con cada uno de sus capítulos dedicados a una "cultura" que se explica de manera endógena e identifica una época del último medio siglo.

Por su parte, la historia formalista puede entenderse como el relato opuesto al sociocultural. A menudo sirve de base a la estructura por estilos, pero también puede constituirse en una narrativa aparte que intenta evitar las inercias asociadas a tales historias. Privilegia los cambios formales que ha experimentado la música, y traza un relato del sonido que presenta la música como autónoma. Es el caso de la narrativa que ofrece Allan Moore en su Rock: The Primary Text (1993, segunda edición de 2001), que discurre únicamente en relación con los cambios formales del rock, o la de Walter Everett (2009) en The Foundations of Rock: From "Blue Suede Shoes" to "Suite: Judy Blue Eyes", libro en el que analiza el sonido del rock entre 1956 y 1969 desde las transformaciones en diferentes instrumentos y parámetros. El propio Moore reivindicó en 2006 este tipo de narrativas centradas en la música como objeto y sonido en un artículo para la revista Popular Music History:

Las historias de la música popular no toman como tema la música, sino los músicos, cantantes, escritores, productores e ingenieros, ejecutivos de discográficas, las discográficas mismas y otras 
instituciones sociales, las cifras de ventas, las culturas y, en ocasiones, incluso los oyentes. Son, por tanto, las historias de agentes cuyo medio de expresión pública o de consumo es la música. [...] Las que se denominan historias de la música popular son más bien historias de los músicos populares y sus entornos. [...] Los analistas de la música y los historiadores podrían colaborar para contar la historia del comportamiento de los sonidos, sin los cuales no habría música popular sobre la que escribir (2006, pp. 330 y 338). ${ }^{4}$

Hay excepciones a estas narrativas, relatos híbridos como Rockin in Time: A Social History of Rock and Roll, de David P. Szatmary (especialmente su octava y última edición, de 2008), Rock and Roll: A Social History, de Paul Friedlander (1996, segunda edición en 2006 con Peter Miller), Rock and Roll: An Introduction, de Michael Campbell (1999, segunda edición en 2008 con James Brody), o las dos últimas ediciones de What's that Sound, de John Covach (2015 y 2018), que combinan en sus historias la trama biográfica, la estilística y la social. Los cuatro son, eso sí, ejemplos evidentes de lo que Keith Negus llamó el "imperialismo del rock": el blues eléctrico de los años cincuenta, la Motown, el soul, el funk, la música disco, el synth-pop, el house y hasta el rap forman parte del género según estos manuales. De hecho, la definición que Covach proporciona del "rock" como "música popular producida específicamente para un público joven" (Covach, 2015, p. 4) es tan omnímoda como etnocéntrica: da por supuesto que pueden englobarse en el rock no solo el electroclash o la música creada para videojuegos, sino también géneros y estilos asociados a la juventud cuyo centro de referencia no son Europa ni Estados Unidos, como el K-pop, el kwaito o el reggaeton.

\section{Historia y progreso}

Independientemente del modelo organizativo que siguen las historias mencionadas, existen confluencias entre ellas. En primer lugar, todas comparten una narrativa lineal y evolutiva que vuelve incompatible el cambio y la disrupción con la continuidad. De hecho, que la asimilación de lo nuevo dentro de lo mayoritario implique su decadencia o su silencio no deja de ser una forma de progreso. Cuando Simon Frith (2007) señala que,

4 "Histories of popular music take as their subjects not music, but musicians, singers, writers, producers and engineers, label executives, labels themselves and other social institutions, sales figures, cultures, and occasionally even listeners. They are thus the stories of agents whose medium of public expression or consumption is music [...] What are called histories of popular music are rather histories of popular musicians and their entourages. [...] Music analysts and historians could collaborate to tell the story of the behaviour of the sounds without which there would be no popular music about which to write". 
de las cinco tramas que él identifica como historias de la música popular (industrial, musicológica, sociológica, histórica y artística), solo la primera implica alguna forma de progreso, acaso cae en una falacia intencional. Si la estabilidad supone la indiferencia, el progreso aflora consciente o inconscientemente. Otra forma común de evolución resulta de atribuir a la música popular del pasado mayor uniformidad que a la del presente. A estos efectos, las etapas más recientes se conciben como una "fragmentación” o “diversificación” (Wall, 2013, p. 14). La década de 1950 en el caso del jazz y la de 1970 en el caso del rock cumplen típicamente esa función, que ayuda a reducir las narrativas posibles y a justificar la hegemonía de un género o estilo en épocas anteriores.

En general, los estudios sobre música popular tienen una deuda con la historia de su recepción. Todas los libros mencionados parten de situar a los creadores solo en el momento de su producción y en el período en que vivieron. En la mayoría de las historias generales del jazz y del rock, las producciones no sobreviven a sus autores, y estos, una vez fallecidos, ya no pueden ser mediadores. Sin embargo, el pasado del jazz y del rock está obviamente lleno de agencias póstumas y contingentes que siguen condicionando su historia (Stanyek y Piekut, 2010; Díaz, 2013; Mendívil, 2013). Atender a su impacto real requeriría repensar nuestros relatos y cronografías actuales. Parafraseando las palabras de Carl Dahlhaus sobre Bach, ${ }^{5}$ la historia del blues en los años treinta podría escribirse con escasas menciones a Robert Johnson, pero no la del blues-rock a partir de los años sesenta; y la historia del rock en los años sesenta podría prácticamente ignorar el Forever Changes de Love, pero no la del rock desde los noventa. Por otra parte, las historias analizadas asumen que lo canónico o lo más visible en el pasado fue también lo mayoritario. Esta idea se ve influida por un vaciado de prensa que tiende a ver las revistas especializadas como una ventana a la realidad pretérita, en lugar de como un medio de difundir gustos específicos y proyectos generacionales, políticos o de campo (Thornton, 1990, p. 93). En España, el protagonismo mediático e historiográfico de la Movida había eclipsado hasta hace poco escenas particularmente dinámicas y multitudinarias del rock durante la transición a la democracia (Del Val Ripollés, 2017; Galicia Poblet, 2017; García Peinazo, 2017; García Salueña, 2017).

Un difícil cometido de las narrativas históricas es el tratamiento de los orígenes y la ruptura. Las historias de la música popular basadas en los

5 “La historia de la música del siglo xviii podría haberse escrito sin Bach o dejándolo de lado, [...] pero no la del siglo XIX" (Dahlhaus, 2003, p. 194). 
orígenes generan a menudo esencialismos y teleologías. En el caso del jazz, por un lado se separa su esencia de su nombre, y por otro se busca retrospectivamente esa esencia en otras músicas. La consecuencia más habitual es que la historia del jazz se remonte a los inicios del ragtime, a principios de la década de 1890, y que, a su vez, el ragtime se explique en función del jazz. También puede ocurrir que, en la habitual competencia historiográfica por desvelar los orígenes, el ragtime no sea suficiente; en consecuencia, se establece una larga cadena genealógica en la que es posible que la historia del jazz sea más breve que la de sus "antecedentes". Lo mismo puede suceder en el rock: Larry Birnbaum y Ed Ward han analizado el hokum, el jazz, el blues de Delta y el boogie como "prehistoria" del rock and roll, condensando medio siglo de música en función de las características de este último (Birnbaum, 2013; Ward, 2016). Si buscar los orígenes de los géneros musicales facilita teleologías y anacronismos, eludir su génesis provoca que estos sean conceptualizados como rupturas radicales respecto al pasado. Esto es frecuente en las narrativas sobre el rock como revolución. Por un lado, hoy sabemos que la recepción del rock and roll se adaptó desde los géneros, estilos y prácticas musicales previas (Wald, 2009, pp. 168-169). Por otro, la ilusoria brecha en la música popular de los años cincuenta se ha naturalizado como realidad a partir de una antítesis entre jazz y rock construida por la crítica musical posterior (Brennan, 2017; Iglesias, 2017).

En relación con estas inercias, otra tarea pendiente de las historias de la música popular es explorar las narrativas no convencionales. En este sentido, podría replantearse la hegemonía del romance como narrativa dominante del jazz y del rock o, al menos, su naturalización. En tanto sirve fundamentalmente a la modernidad y a proyectos ideológicos nacionales, su dominio debe ser cuestionado en tiempos de poscolonialismo, poshumanismo e historia global. Como ha señalado David Scott (2004), quizá sea tiempo de escribir historias como tragedias, relatos del conflicto entre contingencia y libertad, entre la voluntad humana y sus limitaciones materiales. Sin embargo, se trata de una narrativa que también se centra en la lucha: la diferencia entre romance y tragedia es, ante todo, el triunfo o la derrota. La coherencia puede ser una gran enemiga de la historia, plagada de contradicciones. Como ha escrito Sherrie Tucker en una acertada metáfora musical, también como historiadores necesitamos escuchar y disfrutar las disonancias sin buscar necesariamente resoluciones (2012, p. 280). A este respecto, quien escribe estas líneas ha encontrado en la sátira una trama adecuada para narrar los pasados múltiples y aparentemente contradictorios del jazz durante la guerra civil española y el franquismo (Iglesias, 2017). Para el caso del rock y el pop, la narrativa satírica también 
ha sido provechosamente utilizada por el cómic (Bustos, 2019). ${ }^{6}$ Según Hayden White, se trata de una trama antiesencialista, autocrítica y realista, que frustra las expectativas convencionales, es consciente de los problemas del lenguaje, propone la causalidad múltiple y subraya la importancia de la contingencia (White, 1992, p. 46). En este sentido, tragedia y sátira tienen puntos en común: lo que romance y comedia presentan como cambio constante aparece en ellas como caos y "eterno retorno de lo mismo en lo diferente" (White, 1992, p. 22). En otras palabras, una diferencia crucial entre unas y otras es la ausencia o continua presencia del pasado.

\section{Presencias del pasado}

En 2003, Rob Wegman publicó un provocador artículo titulado "Historical Musicology: Is It Still Possible?" en el que se alineaba con los partidarios del giro lingüístico. La investigación histórica, señalaba Wegman, "es fundamentalmente creativa”, expresa quiénes somos. Aquello que llamamos "evidencia histórica" es "la arcilla, el material en bruto, que nos vemos irresistiblemente impulsados a cortar y moldear a nuestra imagen". El conocimiento histórico de la música, concluía, se basa en la mera proyección de nuestra conciencia hacia el pasado, un pasado que no existe, que no tiene "realidad objetiva, ni existencia independiente, ni autonomía, ni alteridad". No es más que el reflejo que el agua de la fuente devuelve a Narciso, su propia imagen, "el producto de nuestra imaginación histórica" (Wegman, 2003, p. 140). ${ }^{7}$

Wegman presuponía así que no hay postura intermedia entre el construccionismo radical y el realismo ingenuo, una idea que confundiría ya entonces a la mayoría de los historiadores, no digamos a los arqueólogos. Como escribió Michael Bentley, "parece que en el cambio de milenio la comunidad de historiadores está harta de ausencia, y con razón" (Bentley, 2006, p. 350). Años antes, Bruno Latour y Reinhart Koselleck habían advertido que quizá no haya asunción más etnocéntrica y presentista que este drástico alejamiento entre realidad y representación, configurado precisamente por la modernidad (Latour, 1991; Koselleck, 2000). El pasado es, por supuesto, "irrecuperable", pero no ha desaparecido por completo.

\footnotetext{
${ }^{6}$ Agradezco especialmente a Irene García Ruano, de la Universidad de Valladolid, que me haya llamado la atención sobre este aspecto.

7 “The past, as we read it into that evidence, has no objective reality, no independent existence, no autonomy, no otherness. Rather, it is always and necessarily the reflection of the viewing subject, the product of our historical imagination". El artículo de Wegman (2011) fue reimpreso sin cambios en la segunda edición del libro The Cultural Study of Music.
} 
Esta persistencia es fundamental para entender cómo sigue condicionando el presente, y es también lo que confiere a la memoria su extraordinario poder contra el olvido y las historias que conciben el pasado como entidad cerrada (Bevernage, 2012). Como bien saben los expertos en el trauma, el pasado se resiste a irse. De ahí el extraordinario valor del trabajo de campo y de la memoria para los estudios sobre música, ya que permiten cuestionar continuamente nuestras narrativas, así como los propios límites sobre los cuales hemos construido el pasado, el presente y el futuro (Bohlman, 2008).

Filósofos de la historia como Eelco Runia, Frank Ankersmit, Chris Lorenz o Herman Paul han escrito por extenso sobre los problemas de equiparar "pasado" y "realidad histórica". Si bien la última ya no existe, el pasado y el presente están interconectados, se cruzan constantemente. En efecto, la historia es más topológica y acumulativa que linear u orgánica (Olsen, 2010, p. 168). Cada nueva fase "se agrega a las anteriores, coexistiendo e interactuando con ellas sin dejarlas en el pasado" (De Landa, 2011, p. 13). Los géneros y estilos de la música popular, así como sus sonidos, sus objetos y sus espacios, conviven y se interrelacionan continuamente. Estas presencias del pasado incluyen la evidente intertextualidad de la música popular, entendida como las relaciones de una creación musical con textos, materiales, prácticas y experiencias precedentes (Lacasse, 2000; Middleton, 2000; Lipsitz, 2007; Spicer, 2009; Williams, 2013; Burns y Lacasse, 2018; Ogas y García Peinazo, 2019), pero van más allá de ella y tienen implicaciones historiográficas cruciales. Robert Kronenburg ha señalado el conflicto que plantea un relato evolutivo de la arquitectura a la hora de escribir una historia de los espacios de la música popular (2019, pp. 9-10). Las narrativas históricas no han de tener por fuerza una naturaleza secuencial (Ankersmit, 2004, p. 72). De hecho, es posible que un relato radicalmente histórico requiera una trama antiesencialista, pero también anticronológica (De Landa, 2011, pp. 9-11). Deleuze y Guattari advirtieron ya en 1980 que "puede que los esquemas de evolución tengan que abandonar el viejo modelo del árbol y de la descendencia" (Deleuze y Guattari, 1988, p. 16).

Berenice Corti, por ejemplo, ha sustituido el desarrollo histórico lineal de los estilos y experiencias musicales por una perspectiva "más cartográfica, extensiva y multidireccional" en su estudio de las significaciones identitarias del jazz en Argentina (Corti, 2015). Por otra parte, Jeremy Barham y David García han propuesto el modelo rizomático de Mil Mesetas como medio de explorar las relaciones entre el jazz y sus otros sin jerarquías ni genealogías lineales (Barham, 2009; García, 2017). Sin embargo, falta 
construir una narrativa rizomática del jazz y del rock que revele el tiempo como un constructo social pero lo mantenga como real, sin ignorar necesariamente las mediaciones sociales del sonido. En este sentido, la aplicación del rizoma a la historia de la música popular no debería producir "la ilusión idealista de que cualquier fenómeno cultural se encuentra despegado de su base material" (Farias, 2010, p. 43). Al contrario, su interés primordial es "conectar eslabones semióticos, organizaciones de poder, circunstancias relacionadas con las artes, las ciencias, las luchas sociales" (Deleuze y Guattari, 1988, p. 13).

Esta perspectiva radicalmente histórica resulta crucial para integrarnos en nuestros propios objetos de estudio, lo que requiere una mayor consciencia de los relatos, pero también de qué los condiciona. Como Paul Ricoeur reprochó a Hayden White, las tramas historiográficas no son una mera cuestión de gustos (Ricoeur, 1985). Una narrativa histórica no es ni un reflejo del pasado, ni una mera proyección sobre él (Ankersmit, 2004, p. 76). Los pasados posibles del jazz y del rock surgen en nuestra intraacción con las fuentes y los vestigios, o se ven limitados por ellos. Han estado tan mediados por las categorías de quienes escribían y el prestigio de sus protagonistas como por instituciones, monumentos, actuaciones musicales y todo tipo de objetos, desde instrumentos a fanzines, partituras o grabaciones. ${ }^{8}$ Necesitamos historias del jazz y del rock como devenir continuo que integren a críticos, historiadores y escritores, en lugar de relatos que los sitúen en un mundo paralelo.

\section{Cuerpo y materialidad}

Este giro ontológico, basado en Walter Benjamin, Henri Bergson y Gilles Deleuze, entre otros, conecta con los recientes giros material y corporal en la historia, que han contribuido a complementar el ineludible estudio de la música popular como proceso. La atención a los objetos, las tecnologías y los cuerpos ha cuestionado así las logocéntricas, etnocéntricas y antropocéntricas máximas que Richard Taruskin plasmó en The Oxford History of Western Music: "el discurso es, de hecho, la historia" y "los agentes solo pueden ser personas" (Taruskin, 2010, p. xviii). ${ }^{9}$ Resulta complicado reducir la música a una perspectiva puramente discursiva, ya que es un proceso que implica instrumentos, partituras, habilidades corporales,

${ }^{8}$ Un buen ejemplo es la Smithsonian Collection of Classic Jazz, conjunto de grabaciones recopilado por Martin Williams y publicado por primera vez en 1973, cuyo efecto canonizador ha sido crucial en todas las historias del jazz desde entonces.

9 "The discourse [...] is in fact the story [...] and agents can only be people". 
sonidos, tecnologías de grabación, espacios y medios de difusión diversos (DeNora, 2014, p. 147). De hecho, la historia de la música popular puede ser un campo propicio para revelar el papel crucial de los cuerpos y los objetos, no ya no como intermediarios, sino como mediadores que permiten, alientan, transforman, modifican y distorsionan (Latour, 2005, pp. 63 y 107).

En primer lugar, el énfasis en el cuerpo implica lidiar con los prejuicios académicos del jazz y del rock contra las formas bailables, que trastocan la preeminencia de la razón impuesta por la modernidad (Quintero Rivera, 2009). Lo físico y lo comercial van siempre de la mano en las historia del blues, el jazz y el rock, como revela el lugar diferenciado que ocupan en ellas el boogie, el swing o el twist, respectivamente. Por otra parte, la función del análisis musical se ha limitado a revelar la construcción de los significados de jazz y del rock. En su libro más ambicioso, Allan Moore señala que "analizar una canción popular es ofrecer una interpretación de ella para determinar qué rango de significados tiene" (2012, p. 5). ${ }^{10} \mathrm{Sin}$ embargo, las narrativas centradas únicamente en el significado abundan en la dualidad cartesiana mente-cuerpo y cuentan solo una parte de la historia de cómo los sonidos son corporeizados. El giro somático subraya formas cognitivas de la música popular que no son únicamente simbólicas (Pelinski, 2000; Gilbert, 2015; Vila, 2017; Díaz y Montes, 2020). En la experiencia musical, la presencia del pasado no se materializa solo voluntaria o racionalmente.

En segundo lugar, la creatividad musical está vinculada a la relación entre músico e instrumento, y este no "transmite" o "materializa" ideas previas, sino que media tanto en aquello que interpretamos, como en lo que componemos, escuchamos y recordamos (Evens, 2005; Ingold, 2013; De Souza, 2017). Nuestra intra-acción con los instrumentos musicales es un buen ejemplo de que, como escribió Paul Connerton, los hábitos corporales se incorporan a través del uso de objetos (Connerton, 1989, p. 94). En sus respectivos y brillantes análisis del virtuosismo de Eddie Van Halen a la guitarra en "Eruption" y de John Coltrane al saxofón tenor en "Acknowledgement", Robert Walser y Lewis Porter olvidan, precisamente, la guitarra y el saxofón tenor (Walser, 1993, pp. 68-75; Porter, 1998, pp. 237-244). No hay mención alguna de Walser a la Frankenstrat de Van Halen, ni a sus pedales y amplificadores, y la breve alusión general de Porter a los Selmer de Coltrane aparece descontextualizada y separada del comentario de sus

10 "To analyse a popular song is to offer an interpretation of it to determinate what range of meaning it has". 
improvisaciones (Porter, 1998, p. 126). Con ello se disocian la técnica y el sonido de estos músicos de sus instrumentos, a la vez que se obvia su conocida obsesión por el equipamiento perfecto. Los instrumentos no solo contribuyen a configurar un "personaje" en el escenario (Auslander, 2006), sino que lo permiten o se resisten a ello de diferentes formas.

De igual modo, la historia de la música popular puede beneficiarse si trata las grabaciones, las partituras e incluso los propios escritos sobre música como objetos mediadores del ensamblaje musical, y no solo como sus representaciones o contenedores. No cabe duda de que las grabaciones han sido el soporte primordial para la canonización del jazz y del rock, hasta el punto de que a menudo su historia se ha reducido a la de sus registros sonoros. La consecuencia es que se reifica el proceso musical en un conjunto de objetos (Small, 1987, pp. 378-380; Rasula, 1995). Ahora bien, como ha señalado Floris Schuiling, el arraigado concepto de las grabaciones como espejismo que falsea la historia del jazz establece implícita y equívocamente que existe un pasado "más real" que el de los discos (Schuiling, 2018, p. 89). Atribuir esa misma idea a los actores del pasado subestimaría la agencia de las grabaciones como mediadoras cruciales en la experiencia y el aprendizaje de la música popular del último siglo, olvidar que no solo han sido productos, sino también desencadenantes de procesos. Por otra parte, integrar las grabaciones y las partituras en el proceso acaso requiera despojarlos de su aura para concebirlos también como objetos físicos, portátiles, coleccionables, tangibles y visibles. En este sentido, cabe reivindicar el valor heurístico que supondría integrar la arqueología en el estudio de la música popular.

Lo mismo ocurre con los espacios y la tecnología, que deben dejar de ser meros receptáculos o transmisores en la historia de la música popular para convertirse en mediadores estéticos ineludibles. Autores como Paul Théberge, Albin Zak, Peter Doyle, Marc Katz, Paul Sanden, Timothy Warner y Samanta Bennett, entre otros, han publicado monografías al respecto, y más recientemente la llamada "musicología de la producción discográfica" (Frith y Zagorski-Thomas, 2012; Zagorski-Thomas, 2014) y los estudios sobre sonido han explorado la importancia de la tecnología en la creación y la percepción musical. También se ha publicado la primera historia arquitectónica de la música popular, sobre los recintos específicamente destinados a ella (Kronenburg, 2019). No obstante, sorprende la facilitad con la que Kronenburg ignora los estudios sobre las tecnologías, fundamentales para configurar los espacios, y falta ver cómo se plasman la fonomusicología y la musicología de la producción discográfica en las historias generales del jazz y del rock. Integrar en el análisis y la historia 
de la música popular el papel de productores e ingenieros de sonido, así como de sus tecnologías y espacios, más allá del lugar todavía secundario o anecdótico que ocupan actualmente, requiere entender la producción musical como un proceso de intra-acciones humanas y no humanas cuya aportación estética y afectiva es tan inexcusable como la composición o el arreglo.

\section{De lo nacional a lo transnacional}

Quizá la tendencia teórica más llamativa en los recientes estudios históricos de la música popular ha sido el giro hacia la transnacionalidad, algo comprensible en una sociedad y un campo académico cada vez más globalizados. En este sentido, se ha intensificado una tendencia que los estudios postcoloniales y de las diásporas iniciaron hace décadas. Ciertamente, como señalan Andy Bennett y Steve Waksman, una de las preocupaciones básicas de los estudios sobre música popular desde finales de los años noventa ha sido aplicar una perspectiva global que complemente y revise las narrativas históricas centradas en el Reino Unido y Estados Unidos (Bennett y Waksman, 2015, p. 5). Desde entonces, el interés por lo transnacional ha generado estudios globales del jazz (Atkins, 2003; Ruesga Bono, 2013; Gebhardt y Whyton, 2015; Johnson, 2016 y 2019; McGee, 2019), el rock (Pacini Hernandez, Fernández l'Hoeste y Zolov, 2004), el metal (Wallach, Berger y Green, 2011; Brown et al., 2016), el glam (Chapman y Johnson, 2016) y el punk (Dunn, 2016; Patton, 2018; Guerra y Quintela, 2020), por citar solo los géneros que nos ocupan. La perspectiva global ha dado lugar incluso a dos prestigiosas series de publicaciones en la editorial Routledge: "Global Popular Music" y "Transnational Studies in Jazz".

Huelga decir que muchos de estos proyectos de historia transnacional de la música popular son, en realidad, proyectos plurinacionales, que no es lo mismo. Estos últimos tienen como objetivo ampliar el canon de los casos estudiados, dando voz a países académicamente subrepresentados, o bien mostrar la pluralidad de las escenas nacionales. Sin embargo, esta historia inclusiva no ha ido acompañada de cambios en los criterios o modelos explicativos convencionales (Bohlman y Plastino, 2016, p. 9). Un cambio en la perspectiva geográfica, sin más, no tiene por qué subvertir las narrativas dominantes sobre el jazz (Schenker, 2018, p. 231). Por el contrario, en sus diversas tendencias (historia comparada, world history, transnational history, connected history, histoire croisée o entangled history), la historia global no busca elaborar un relato universal, sino mostrar que el pasado se ha transformado a través de relaciones e influencias recíprocas, en las que no existe 
un centro que pueda ser aislado como único actor determinante (Conrad, 2016, p. 4). Tal agenda empieza a cuestionar lecturas excepcionalistas del jazz o del rock como algo "creado" en Estados Unidos y el Reino Unido, y luego progresivamente "recibido" o "asimilado" en otros países. Del mismo modo, otros estudios han propuesto nuevos marcos y redes desde los que estudiar estos géneros musicales, alejados de los cánones y circuitos anglosajones (González, 2013; Ruesga Bono, 2013; Viñuela, 2019).

Una parte de la historia global ha emprendido una particular cruzada contra el Estado-Nación como entidad de análisis de la música popular. Desde una corriente decididamente proclive al enfoque transnacional como los llamados New Jazz Studies, por ejemplo, se han subrayado "las limitaciones de los contextos nacionales como constructos analíticos" (Gebhardt, 2012, p. 186). Sin embargo, las naciones no son solo "constructos analíticos", y desde luego no lo son más que "Europa", "el mundo" o "el Atlántico negro". Uno de los peligros de lo global es olvidar la relevancia de los Estados-Nación, realidades geopolíticas que configuran procesos y redes culturales y materiales, como agentes ineludibles de la historia contemporánea. El precio de deconstruir la nación no puede ser anularla. Como escribió Pablo Alabarces a propósito de la pretendida universalidad del rock: "El fútbol también es universal. Pero en todos lados se juega distinto" (Alabarces, 1993, p. 29). Es más, una historia nacional del jazz o del rock puede ser considerablemente más subversiva que una global. Si se cuestiona el Estado-Nación como objeto de estudio, pero se apuntalan sus ontologías y narrativas, simplemente se globalizan sus cronotipos. Lo transnacional no debe sustituir otras escalas historiográficas, sino complementarlas. Quizá el error consiste en pensar que la música popular de una nación se desarrolla dentro de sus fronteras, cuando a menudo se construye sobre ellas, en interacción con sus representaciones globales (Zuberi, 2001; Regev, 2004; Madrid, 2008; Karush, 2017).

En este sentido, otro riesgo es que las historias transnacionales del jazz y del rock sigan reproduciendo los mismos enfoques convencionales y etnocéntricos. El lema de lo relacional y su énfasis en las coincidencias puede obliterar la pluralidad y la excepción. Si entendemos la diáspora de un género musical como una adaptación lineal a diversos lugares, solo reemplazamos un modelo evolucionista (darwiniano) por otro (lamarckiano). Con ello puede incurrirse en tres sesgos fundamentales: en primer lugar, equiparar epistemes y entornos materiales diversos; en segundo lugar, suprimir tanto la causalidad múltiple como la heterotemporalidad; y, por último, fosilizar la hegemonía de los mismos centros. Por ejemplo, que la aproximación más completa y reciente a una historia transnacional del jazz utilice solo bibliografía en inglés (Johnson, 2020) constituye una 
paradoja, cuando no otra prueba del imperio. Las historias más completas e informadas del jazz en Francia, Alemania, Italia, España, Portugal y todos los países de Latinoamérica, excepto Cuba, están publicadas exclusivamente en francés, alemán, italiano, español o portugués. Si las historias transnacionales del jazz y del rock van a escribirse solo a partir del inglés, dejarán fuera buena parte de los estudios más relevantes sobre el género y, lo que es más grave, incluirá solo países que ya tengan bibliografía en ese idioma. Paradójicamente, por tanto, el gran riesgo actual de la historia diaspórica es tanto silenciar al subalterno como obviar las asimetrías producidas por siglos de colonialismo.

Cabe apuntar al menos un peligro más: convertir las historias transnacionales de la música popular en meras síntesis o ejercicios teóricos, alejándolas de buena parte de sus fuentes primarias o naturalizando sus mediaciones y sus lógicas locales de preservación documental (Subrahmanyam, 2014). Los relatos transnacionales tienden a constatar, más que explicar, la globalidad de los intercambios (Torre, 2018, p. 51). En este sentido, el fácil recurso a la "influencia" elimina sus mediadores concretos (Piekut, 2014, p. 202). Tony Whyton ha subrayado la capacidad de la microhistoria para iluminar procesos globales y subvertir las convenciones historiográficas del jazz manteniendo una interpretación apegada al archivo (Whyton, 2019). Ahora bien, no debe equipararse microhistoria e historia local, ni naturalizar esta última como antítesis de la historia dominante. Los casos de Nueva Orleans, Memphis o Birmingham muestran que las historias locales también pueden contribuir eficazmente a crear y consolidar mitos del jazz y del rock. La cohesión de las historias de la música popular dependerá de nuestra destreza para que sean, a la vez, locales, nacionales y globales, así como de que especifiquen redes y mediaciones, no solo paralelismos e influencias. Por otra parte, conviene pensar los archivos no solo como lugares de preservación documental, sino también como procesos en los que se han ido codificando relaciones de poder y regímenes de verdad, además de contingencias y transgresiones. El reto es concebir el archivo como un espacio político múltiple y heterogéneo, que exige, desentrañas las lógicas de sus criterios y silencios a la vez que permite aprovechar sus azares e incongruencias (Steedman, 2002; Stoler, 2010; Povinelli, 2016, pp. 148-150).

\section{Conclusión}

$\mathrm{Si}$, como demuestran los estudios recientes, la identidad actual de los géneros musicales no se puede explicar sin su historia, se vuelve ineludible una mayor reflexión sobre el tiempo y la causalidad en la música popular. 
Ese mismo nexo entre pasado y presente reclama una mayor consciencia de las narrativas históricas como partes constitutivas de los ensamblajes del jazz y del rock. Al fin y al cabo, revelan cómo nos situamos en esa historia que incluye "lo que han hecho sus miembros, a lo hay que añadir la historia de lo que dicen que han hecho y la historia de cómo han llegado a decirlo" (Pocock, 2012, p. 274). Una internacionalización real de los estudios sobre el jazz y el rock debería cuestionar sus ontologías, conceptos, temporalidades y narrativas más arraigadas. De hecho, quizá el principal valor de las historias de la música popular no es tanto documentar las experiencias del pasado como desnaturalizar, decolonizar y desestabilizar el presente. Cada nuevo pasado abre nuevas posibilidades futuras. Este artículo ha propuesto que las historias de la música popular deben seguir modelos menos orgánicos, evolutivos, antropocéntricos, androcéntricos y logocéntricos, que atiendan a temporalidades múltiples y causalidades no lineales, compatibilicen ruptura y estabilidad histórica, afronten la larga duración, iluminen las asimetrías, muestren la porosidad de los géneros musicales, no equiparen lo más visible o lo canónico a lo mayoritario, integren la contingencia en la génesis, se preocupen por los efectos más que por las causas, no igualen discurso y práctica, sitúen a los creadores en su proceso completo de recepción, y propongan un mayor equilibrio entre procesos, objetos y eventos. Como ha señalado Elizabeth Grosz, no podemos cambiar la realidad histórica, pero sí podemos iluminarla mediante formas y perspectivas diversas para transformar el presente a través del pasado (2004, p. 252). 


\section{Bibliografía}

" Altschuler, G. C. (2003). All Shook Up: How Rock'n'Roll Changed America. New York: Oxford University Press.

» Alabarces, P. (1993). Entre gatos y violadores: el rock nacional en la cultura argentina. Buenos Aires: Colihue.

»Ankersmit, F. (2004). Historia y tropología. México: Fondo de Cultura Económica.

» Atkins, E. T. (Ed.). (2003). Jazz Planet. Jackson: University Press of Mississippi.

» Auslander, P. (2006). Musical Personae. The Drama Review, 50(1), 100-119.

»Baker, S. et al. (2018). The Routledge Companion to Popular Music History and Heritage. New York: Routledge.

" Barad, K. (2007). Meeting the Universe Halfway: Quantum Physics and the Entanglement of Matter and Meaning. Durham: Duke University Press.

» Barham, J. (2009). Rhizomes and Plateaus: Rethinking Jazz Historiography and the Jazz-Classical Relationship. Jazz Research Journal, 3(2), 171-202.

»Bennett, A. (2001). Cultures of Popular Music. Berkshire: Open University Press.

" Bennett, A., Shank, B. y Toynbee, J. (Eds.). (2006). The Popular Music Studies Reader. New York: Routledge.

» Bennett, A. y Waksman, S. (Eds.). (2015). The SAGE Handbook of Popular Music. London: SAGE.

»Bentley, M. (2006). Past and "Presence": Revisiting Historical Ontology. History and Theory, 45, 349-361.

»Berendt, J. E. (1998). El jazz: de Nueva Orleans a los años ochenta. Madrid: Fondo de Cultura Económica.

» Bevernage, B. (2012). History, Memory, and State-Sponsored Violence: Time and Justice. New York: Routledge.

» Birnbaum, L. (2013). Before Elvis: The Prehistory of Rock ' $n$ ' Roll. Lanham: Scarecrow.

» Blesh, R. (1947). Shining Trumpets: A History of Jazz. New York: Alfred A. Knopf.

» Bohlman, P. V. (2008). Returning to the Ethnomusicological Past. En G. F. Barz and T. J. Cooley (Eds.). Shadows in the Field. New Perspectives for Fieldwork in Ethnomusicology, second edition (pp. 246-270). New York and Oxford: Oxford University Press.

» Bohlman, P. V. y Plastino, G. (Eds.). (2016). Jazz Worlds/World Jazz. Chicago: The University of Chicago Press.

»Born, G. and Barry, A. (2018). Music, Mediation Theories and Actor-Network 
Theory. Contemporary Music Review, 37(5-6), 443-487.

" Brackett, D. (2016). Categorizing Sound: Genre and Twentieth-Century Popular Music. Oakland: University of California Press.

»Brennan, M. (2017). When Genres Collide: Down Beat, Rolling Stone, and the Struggle Between Jazz and Rock. New York: Bloomsbury.

»Brown, A. et al. (2016). Global Metal Music and Culture: Current Directions in Metal Studies. New York: Routledge.

» Burns, L. y Lacasse, S. (2018). The Pop Palimpsest: Intertextuality in Recorded Popular Music. Ann Arbor: University of Michigan Press.

» Bustos, L. (2019). Pop: ;No me quito esa canción de la cabeza! Madrid: Caramba.

» Campbell, M. y Brody, J. (2008). Rock and Roll: An Introduction. Belmont: Thomson.

" Chambers, I. (1985). Urban Rhythms. New York: St. Martin's.

"Chapman, I. y Johnson, H. (2016). Global Glam and Popular Music: Style and Spectacle from the 1970s to the 2000s. New York: Routledge.

» Charlton, K. (2014 [1990]). Rock Music Styles: A History. Boston: McGraw-Hill.

"Clarke, D. (1995). The Rise and Fall of Popular Music: A Narrative History from the Renaissance to Rock'n'Roll. New York: St. Martin's Press.

»Connerton, P. (1989). How Societies Remember. Cambridge: Cambridge University Press.

» Conrad, S. (2016). What is Global History? Princeton: Princeton University Press.

»Corti, B. (2015). Jazz argentino, la música "negra" del país "blanco". Buenos Aires: Gourmet Musical.

" Covach, J. (2018 [2006]). What's that Sound: An Introduction to Rock and Its History. New York: Norton.

»Dahlhaus, C. (2003 [1977]). Fundamentos de la historia de la música. Barcelona: Gedisa.

» DeCurtis, A., Henke, J. y George-Warren, H. (Eds.). (1992). The Rolling Stone Illustrated History of Rock and Roll. New York: Random House.

»De Landa, M. (2011). Mil años de historia no lineal. Barcelona: Gedisa.

»Del Val Ripollés, F. (2017). Rockeros insurgentes, modernos complacientes: un análisis sociológico del rock en la Transición (1975-1985). Madrid: SGAE.

»Deleuze, G. y Guattari, F. (1988). Mil mesetas: capitalismo y esquizofrenia. Valencia: Pre-Textos.

»DeNora, T. (2014). Making Sense of Reality: culture and perception in everyday life. London: SAGE.

»De Souza, J. (2017). Music at Hand: Instruments, Bodies, and Cognition. New York: Oxford University Press.

»DeVeaux, S. (1991). Constructing the Jazz Tradition: Jazz Historiography. Black American Literature Forum, 25(3), 525-560. 
”DeVeaux, S. y Giddins. G. (2009). Jazz. New York: Norton.

" Díaz, C. F. (2013). Recepción y apropiación de músicas populares: dispositivos de enunciación, lugares sociales e identidades. El Oído Pensante 1(2), 7-22. Recuperado de http://revistascientificas.filo.uba.ar/index.php/ oidopensante/article/view/7074

»Díaz, C. F. y Montes, M. Á. (2020). Músicas populares, cognición, afectos e interpelación. Un abordaje socio-semiótico. El Oído Pensante 8(2), 38-64. Recuperado de http://revistascientificas.filo.uba.ar/index.php/ oidopensante/article/view/8058

»Drott, E. (2013). The End(s) of Genre. Journal of Music Theory, 57(1): 1-46.

»Dunn, K. C. (2016). Global Punk: Resistance and Rebellion in Everyday Life. London: Bloomsbury.

» Ennis, P. H. (1992). The Seventh Stream: The Emergence of Rock'n'Roll in American Popular Music. Hanover: Wesleyan University Press.

»Evens, A. 2005. Sound Ideas: Music, Machines, and Experience. Minneapolis: University of Minnesota Press.

"Everett, W. (2009). The Foundations of Rock: From "Blue Suede Shoes" to "Suite: Judy Blue Eyes". New York: Oxford University Press.

》Fabbri, F. (2012). How Genres are Born, Change, Die: Conventions, Communities and Diachronic Processes. En S. Hawkins (Ed.). Critical Musicological Reflections (pp. 179-191). Aldershot: Ashgate.

»Farias, B. (2010). A crítica dialética e o hibridismo musical na atualidade. Resonancias, 27, 39-55.

» Friedlander, P. y Miller, P. (2006). Rock and Roll: A Social History. Boulder: Westview Press.

»Frith, S. (2007). Can Music Progress?: Reflections on the History of Popular Music. Musicology, 7, 247-257.

" Frith, S. y Zagorski-Thomas, S. (Eds.). (2012). The Art of Record Production An introductory Reader for a New Academic Field. Farnham: Ashgate.

» Gaar, G. (1992). She's a Rebel: The History of Women in Rock \& Roll. Seattle: Seal.

»Galicia Poblet, F. (2017). Inoxidable. Formación, cristalización y crecimiento del Heavy Metal en España (1978-1985). Madrid: Apache.

"García, D. A. (2017). Listening for Africa: Freedom, Modernity, and the Logic of Black Music's African Origins. Durham: Duke University Press.

》 García Peinazo, D. (2017). Rock andaluz: significación musical, identidades e ideología en la España del tardofranquismo y la transición (1969-1982). Madrid: SEdeM.

» García Salueña, E. (2017). Música para la libertad. Nuevas tecnologías, experimentación y procesos de fusión en el rock progresivo de la España de la Transición: el eje noroeste. Avilés: Norte Sur.

» Gebhardt, N. (2012). When Jazz Was Foreign: Rethinking Jazz History. 
Jazzforschung, 44, 185-197.

" Gebhardt, N. y Whyton, T. (2015). The Cultural Politics of Jazz Collectives: This Is Our Music. New York: Routledge.

» Gennari, J. (2006). Blowin' Hot and Cool: Jazz and Its Critics. Chicago: The University of Chicago Press.

» Giddins, G. (1998). Visions of Jazz: The First Century. New York: Oxford University Press.

» Gilbert, J. (2015). From Signification to Affect. En J. Shepherd y K. Devine (Eds.). The Routledge Reader on the Sociology of Music (pp. 369-376). New York: Routledge.

» Gillett, C. (1970). The Sound of the City: The Rise of Rock and Roll. New York: Outerbridge-Dienstfrey.

" Gioia, T. (2010). Blues. La música del Delta del Mississippi. Madrid: Turner.

» Gioia, T. (2018 [1997]). The History of Jazz. New York: Oxford University Press.

» González, J. P. (2013). Pensar la música desde América Latina: problemas e interrogantes. Santiago de Chile: Universidad Alberto Hurtado.

» Gridley, M. (2011 [1978]). Jazz Styles: History and Analysis. 11 edition. Uppersaddle River, NJ: Pearson Education.

»Griffiths, D. (2019). Reseña de Stories We Could Tell: Putting Words to American Popular Music de D. Sanjek. Popular Music, 38(3), 584-587.

» Grosz, E. (2004). The Nick of Time: Politics, Evolution, and the Untimely. Crows Nest: Allen \& Unwin.

» Guerra, P. y Quintela, P. (2020). Punk, Fanzines and DIY Cultures in a Global World: Fast, Furious and Xerox. London: Palgrave.

»Guerrero, J. (2010). Cómo se cuenta la historia: criterios historiográficos en la cronología del rock nacional. En M. A. García (Ed.), Rock en papel: bibliografía crítica de la producción académica sobre el rock en Argentina (pp. 65-72). La Plata: Universidad Nacional de La Plata.

»Hamm, C. (2004). Popular Music and Historiography. Popular Music History, 1(1), 9-14.

» Hardie, D. (2013). Jazz Historiography: The Story of Jazz History Writing. Bloomington: iUniverse.

» Hartog, F. (2003). Régimes d'historicité. Présentisme et expérience du temps. Paris: Le Seuil.

» Iglesias, I. (2017). La modernidad elusiva: jazz, baile y política en la guerra civil española y el franquismo. Madrid: CSIC.

» Ingold, T. (2013). Making: Anthropology, Archaeology, Art and Architecture. London and New York: Routledge.

» Johnson, B. (Ed.) (2016). Jazz and Totalitarianism. New York: Routledge.

»Johnson, B. (2018). Problematising Popular Music History in the Context of Heritage and Memory. En S. Baker et al. (Eds.), The Routledge Companion to 
Popular Music History and Heritage (pp. 13-25). New York: Routledge.

» Johnson, B. (2020). Jazz Diaspora: Music and Globalisation. New York: Routledge.

» Karush, M. B. (2017). Musicians in Transit: Argentina and the Globalization of Popular Music. Durham: Duke University Press.

»Kearney, M. C. (2005). The Missing Links: Riot Grrrl - Feminism - Lesbian Culture. En S. Whiteley (Ed.). Sexing the Groove: Popular Music and Gender (pp. 207-229). New York: Routledge.

» Koselleck, R. (2000). Zeitschichten. Studien zur Historik. Frankfurt a. M.: Suhrkamp.

»Kronenburg, R. (2019). This Must Be the Place: An Architectural History of Popular Music Performance Venues. New York: Bloomsbury.

"Lacasse, S. (2000). Intertextuality and Hypertextuality in Recorded Popular Music. En M. Talbot (Ed.). The Musical Work: Reality or Invention? (pp. 35-58). Liverpool: Liverpool University Press.

" Latour, B. (1991). Nunca fuimos modernos. Madrid: Siglo XXI.

»Latour, B. (2008). Reensamblar lo social. Buenos Aires: Manantial.

» Lipsitz, G. (2007). Footsteps in the Dark: The Hidden Histories of Popular Music. Minneapolis: University of Minnesota Press.

»Liska, M. (2014). Estudios de género y diversidades sexo-genéricas: dicotomías y encrucijadas analíticas en las investigaciones sobre música popular. El Oído Pensante, 2(2), 1-21. Recuperado de http:// revistascientificas.filo.uba.ar/index.php/oidopensante/article/ view/7443/6657

" Lomax, A. (1993). The Land Where the Blues Began. New York: Pantheon.

" Madrid, A. L. (2008). Nor-tec Rifa!: Electronic Dance Music from Tijuana to the World. New York: Oxford University Press.

" McGee, K. (2019). Remixing European Jazz Culture. New York: Routledge.

"Mendívil, J. (2013). The Song Remains the Same? Sobre las biografías sociales y personalizadas de las canciones. El Oído Pensante, 1(2), 23-49. Recuperado de http://revistascientificas.filo.uba.ar/index.php/oidopensante/article/ view/7075

» Middleton, R. (1990). Studying Popular Music. Milton Keynes: Open University Press.

» Middleton, R. (2000). Work-in(g)-Practice: Configurations of the Popular Music Intertext. En M. Talbot (Ed.). The Musical Work: Reality or Invention? (pp. 59-87). Liverpool: Liverpool University Press.

»Moore, A. (1993 [2001]). Rock: The Primary Text. Aldershot: Ashgate.

" Moore, A. (2006). What Story Should a History of Popular Music Tell? Popular Music History, 1(3), 329-338.

» Moore, A. (2012). Song Means: Analysing and Interpreting Recorded Popular Song. Franham: Ashgate. 
» Myers, M. (2013). Why Jazz Happened. Los Angeles: University of California Press.

» Negus, K. (1996). Popular Music in Theory. An Introduction. Cambridge: Polity Press.

" O'Brien, L. (1996). She Bop: The Definitive History of Women in Rock, Pop \& Soul. New York: Penguin.

» O'Dair, B. (Ed.). (1997). Trouble Girls: The Rolling Stone Book of Women in Rock. New York: Random House.

» Ogas, J. y García Peinazo, D. (2019). Dosier "Análisis musical y prácticas híper/intertextuales en la música iberoamericana". Cuadernos de Música Iberoamericana 32, 11-185.

" Olsen, B. (2010). In Defense of Things. Archaeology and the Ontology of Objects. Lanham: AltaMira.

" O'Meally, R., Edwards, B. H. and Griffin, F. J. (Eds.). (2004). Uptown Conversation: The New Jazz Studies. New York: Columbia University Press.

" Ortiz Oderigo, N. (1952). Historia del jazz. Buenos Aires: Ricordi.

»Pacini Hernandez, D., Fernandez l'Hoeste, H. y Zolov, E. (2004). Rockin Las Americas. The Global Politics of Rock in Latin/o America. Pittsburgh: University of Pittsburgh Press.

»Panassié, H. (1942). The Real Jazz. New York: Smith \& Durrell.

»Palmer, R. (1982). Deep Blues: A Musical and Cultural History of the Mississippi Delta. New York: Penguin.

» Patton, R. A. (2018). Punk Crisis: The Global Punk Rock Revolution. New York: Oxford University Press.

»Pelinski, R. (2000). Invitación a la etnomusicología. Quince fragmentos y un tango. Madrid: Akal.

"Piekut, B. (2014). Actor-Networks in Music History: Clarifications and Critiques. Twentieth-Century Music, 11, 191-215.

»Pocock, J. G. A. (2012). Pensamiento político e historia. Ensayos sobre teoría y método. Madrid: Akal

» Porter, L. (1998). John Coltrane: His Life and Music. Ann Arbor: University of Michigan Press.

"Povinelli, E. (2016). Geontologies: A Requiem to Late Liberalism. Durham: Duke University Press.

»Prouty, K. (2010). Toward Jazz's “Official” History: The Debates and Discourses of Jazz History Textbooks. Journal of Music History Pedagogy 1(1), 19-43.

»Quintero-Rivera, Á. (2009). Cuerpo y cultura: Las músicas «mulatas» y la subversión del baile. Madrid: Iberoamericana/Vervuert.

»Ramos, P. (2010). Luces y sombras en los estudios sobre las mujeres y la música. Revista Musical Chilena, 64(213), 7-25.

» Ramsey, F. Jr. y Smith, C. E. (Eds.). (1939). Jazzmen. New York: Harcourt Brace. 
" Rasula, J. (1995). The Media of Memory: The Seductive Menace of Recordings in Jazz History. En K. Gabbard (Ed.). Jazz among the Discourses (pp. 134-162). Durham: Duke University Press.

» Regev, M. (2004). Popular Music and National Culture in Israel. Los Angeles: University of California Press.

» Reynolds, S. (2012). Retromanía: La adicción del pop a su propio pasado. Buenos Aires: Caja Negra.

»Ricoeur, P. (1985). Tiempo y narración. Madrid: Cristiandad.

» Ruesga Bono, J. (2013). Jazz en español: derivas hispanoamericanas. Xalapa: Universidad Veracruzana.

»Sanjek, D. (2019). Stories we Could Tell: Putting Words to American Popular Music. New York: Routledge.

"Schenker, F. J. (2018). Listening for Empire in Transnational Jazz Studies. En N. Gebhardt, N. Rustin-Paschal y T. Whyton (Eds). The Routledge Companion to Jazz Studies (pp. 231-238). New York: Routledge.

»Schuller, G. (1989). The Swing Era. New York: Oxford University Press.

»Schuling, F. (2019). Jazz and the Material Turn. En N. Gebhardt, N. Paschal y T. Whyton (Eds.). The Routledge Companion to Jazz Studies (pp. 87-96). New York: Routledge.

»Scott, D. (2004). Conscripts of Modernity: The Tragedy of Colonial Enlightenment. Durham: Duke University Press.

"Small, C. (1987). Music of the Common Tongue. London: Calder.

»Stanyek, J. y Piekut, B. (2010). Deadness: Technologies of the Intermundane. The Drama Review, 54(1), 14-38.

»Spicer, M. (2009). Strategic Intertextuality in Three of John Lennon's Late Beatles Songs. Gamut: Online Journal of the Music Theory Society of the MidAtlantic, 2(1), 347-375.

»Steedman, C. K. (2002). Dust: The Archive and Cultural History. New Brunswick, N.J.: Rutgers University Press.

"Stoler, A. L. (2009). Along the Archival Grain. Epistemic Anxieties and Colonial Common Sense. Princeton: Princeton University Press.

»Stuessy, J. y Lipscomb, S. D. (2012 [1990]). Rock and Roll: Its History and Stylistic Development. Boston: Pearson.

»Subrahmanyam, S. (2014). Aux origines de l'histoire globale. París: Collège de France/Fayard.

»Szatmary, D. P. (2008). Rockin in Time: A Social History of Rock and Roll. Boston: Pearson.

» Taruskin, R. (2010). The Oxford History of Western Music, vol. 1. New York: Oxford University Press.

»Thornton, S. (1990). Strategies for Reconstructing the Popular Past. Popular Music, 9(1), 87-95.

» Tirro, F. (2016 [1977]). Jazz: A History. New York: Norton. 
»Torre, A. (2018). Micro/macro: ¿local/global? El problema de la localidad en una historia espacializada. Historia crítica, 69, 37-67.

» Tucker, S. (2012). Deconstructing the Jazz Tradition: The Subjectless Subject of New Jazz Studies. En D. Ake, C. H. Garrett y D. Goldmark. Jazz/Not Jazz: The Music and Its Boundaries (pp. 264-284). Berkeley: University of California Press.

» Vélez, A. (2018). Mujeres del rock. Su historia. Barcelona: Robinbook.

»Vila, P. (1996). Identidades narrativas y música. Una primera propuesta para entender sus relaciones. Trans: Revista Transcultural de Música, 2. Recuperado de https://www.sibetrans.com/trans/articulo/288/ identidades-narrativas-y-musica-una-primera-propuesta-para-entendersus-relaciones

»Vila, P. (Ed.). (2017). Music, Dance, Affect, and Emotions in Latin America Music, Culture, and Identity in Latin America. Lanham: Lexington.

»Viñuela, E. (2019). Rock en español: un terreno de disputa y convergencia entre España y Latinoamérica. Resonancias, 23(45), 197-214.

»Wald, E. (2009). How the Beatles Destroyed Rock'n'Roll: An Alternative History of American Popular Music. New York: Oxford University Press.

»Wall, T. (2013). Studying Popular Music Culture. London: SAGE.

»Wallach, J., Berger, H. y Green, P. D. (Eds.). (2011). Metal Rules the Globe: Heavy Metal Music around the World. Durham: Duke University Press.

»Walser, R. (1993). Running with the Devil: Power, Gender, and Madness in Heavy Metal Music. Middletown, CT: Wesleyan University Press.

»Ward, E. (2016). The History of Rock \& Roll, Volume One, 1920-1963. New York: Flatiron.

»Weber, E. T. (2016). The Beatles and the Historians: An Analysis of Writing about the Fab Four. Jefferson: McFarland.

»Wegman, R. (2003). Historical Musicology: Is It Still Possible? En M. Clayton, T. Herbert y R. Middleton (Eds.). The Cultural Study of Music (pp. 136-145). New York: Routledge.

»White, H. (1992). Metahistoria: La imaginación histórica en la Europa del siglo xix. México D.F.: Fondo de Cultura Económica.

»Whyton, T. (2019). Wilkie's Story: Dominant Histories, Hidden Musicians, and Cosmopolitan Connections in Jazz. En N. Gebhardt, N. Rustin-Paschal y T. Whyton (Eds). The Routledge Companion to Jazz Studies (pp. 3-15). New York: Routledge.

»Williams, J. A. (2013). Rhymin' and Stealin': Musical Borrowing in Hip-Hop. Ann Arbor: University of Michigan Press.

»Zagorsky-Thomas, S. (2014). The Musicology of Record Production. Cambridge: Cambridge University Press.

»Zuberi, N. (2001). Sounds English: Transnational Popular Music. Chicago: University of Illinois Press. 


\section{Biografía / Biografia / Biography}

\section{Iván Iglesias}

Profesor titular de música popular urbana en la Universidad de Valladolid. Es Licenciado en Historia Contemporánea y en Historia y Ciencias de la Música, y Doctor en Musicología. Ha sido investigador y profesor visitante en The City University of New York, Freie Universität Berlin, Cardiff University, Sapienza Università di Roma y Universidad de La Habana. Entre 2008 y 2014 fue miembro de la Junta Directiva de la SIBE-Sociedad de Etnomusicología, y en la actualidad forma parte del consejo editorial de Revista de Musicología y Cuadernos de Música Iberoamericana, entre otras revistas, así como del comité de publicaciones de la Sociedad Española de Musicología. Su primer libro, La modernidad elusiva: jazz, baile y política en la guerra civil española y el franquismo (CSIC, 2017) fue galardonado en 2018 con el Premio Nacional a la Mejor Monografía en Arte y Humanidades por la Unión de Editoriales Universitarias Españolas, y en 2019 con el IASPM Book Prize al mejor libro sobre música popular urbana en lengua no inglesa publicado en los años 2017 y 2018. 